\title{
Legal Issues of Rural Financial Supervision System in China
}

\author{
JIANG Xu-song
}

Huazhong Agricultural University

Keywords: Rural finance; supervision system; legal analysis

\begin{abstract}
This paper aims at studying the legal issues of rural financial supervision system in China, and tries to solve the problems. For this objective, this paper mainly analyzes the reality demands of rural financial supervision system, to demonstrate the significance of perfecting the supervision system. Then, based on the investigation and discussion, the concept for perfecting Chinese rural financial supervision system is proposed. It mainly includes the following aspects: firstly, improve legislation and improve the legal system of rural financial supervision. Secondly, set reasonable supervision objectives, adopt suitable rural financial regulation, establish a complete quality control mechanism and corporate governance structure, so as to implement fostering rural financial endogenous power supervision concept. Thirdly, give full play to and strengthen the policy oriented and financial regulatory functions of the Ministry of Agriculture and policy oriented finance in rural areas. At last, improve the social credit checking system, agricultural insurance system and deposit insurance, so as to construct complete rural financial risk prevention system and market withdrawal mechanism. In conclusion, the improvement of rural financial supervision system needs the efforts of various aspects. And only by the joint effort can the legal problems be solved efficiently.
\end{abstract}

\section{Introduction}

The rural finance has the characteristics different from city commercial finance, involving a wide range, high risk and strong policy. At the same time, the rural finance of our country presents the dualistic structure with coexistence of formal and informal finance, and in the system, it also includes the financial organizations with different levels and patterns. Therefore, although the construction of unified financial regulatory framework is the objective of the financial industry development, at this stage, it is still doubtful whether the rural financial supervision can be achieved by the supervision standards and means suitable for urban financial business [1].

Moreover, China's rural finance has the problems that the development of endogenous forces lags behind, the supply of financial service is insufficient, the financing channel is not smooth and even capital back-flow exists. These problems result in that China's existing rural financial market is difficult to meet the effective demand of rural finance, and even becomes the bottleneck and obstacle that restricts the development of rural economic society and the new rural construction. In view of this, based on the analysis on the investigation of development status of China's rural finance and analysis of rural financial supervision lack, this paper mainly adopts the analysis method of empirical investigation and comparison analysis. In addition, based on clarifying the above mentioned problems, it puts forward an idea to perfect the financial supervision system in rural areas of our country.

\section{Analysis of the current situation of rural financial supervision system in China}

The rural finance in China has its own complexity. On the one hand, restricted by the actual conditions of agricultural country and the urban and rural binary economic structure, it results in that China's rural development lags behind. And agricultural economy is underdevelopment, natural risk is high, and farmers' ability to resist risks is low. As a result, the rural financial market is weak, and the sustainable development is insufficient. Because the reform of rural financial system is relatively backward, formal finance has exposed more and more problems in the allocation of capital in the process of rural economic development in China." On the other hand, the state-owned commercial 
banks abolish and merge the rural grassroots organizations, and the cooperation of rural credit cooperatives is alienating and facing financial difficulties [2]. Moreover, the new rural financial institutions, such as rural banks, loan companies and rural mutual cooperatives rise sharply. The too complex rural financial status not only needs the financial supervision, but also needs to guarantee the benign operation of the rural financial system. It is also necessary to protect the legitimate interests of stakeholders, thereby enhancing the endogenous force of rural finance, stabilizing the rural financial order, and maintaining rural financial security, which provides effective and sufficient financial support for rural and agricultural economic development. The existing rural financial supervision in China has obviously failed to meet this requirement. At least there are the following deficiencies and drawbacks:

Lacking regulatory resources and difficult to form effective regulatory force. The rural financial supervision in China cannot be distinguished from the urban financial supervision, and the main regulatory body is still traditional "One line, three meetings". This supervision pattern has many deficiencies in dealing with rural financial supervision:

For "One line, three meetings" regulatory body, it is difficult to reflect and realize the policy orientation and demand of rural finance. A major feature of rural finance is a strong policy nature. Its financial activities need to be linked with the national agricultural policy, so as to adapt to the different requirements of the country in different stages for the development of rural finance capital support. "One line, three meetings", as the main regulatory body of rural finance, is difficult to express and transmit the agricultural policies of the country in a timely and flexible manner.

The rural financial supervision has not attracted enough attention, and the resources of rural financial supervision in the existing financial supervision system are seriously insufficient. When it comes to the rural financial system, the main regulatory body is the CBRC (China Banking Regulatory Commission), and in accordance with the corresponding division of labor, the regulatory responsibilities of rural small and medium-sized financial institutions are subordinate to the local banking regulatory bureau in accordance with the principle of territoriality [3]. But "China's rural financial institutions has the characteristics of small institutions and long chain. The vast majority of small and medium-sized rural financial institutions are located in the county (city), township (town) and administrative villages, only regulatory offices are set within its jurisdiction. These offices do not have the qualification of independent regulatory body, and generally only 3-5 people's supervisors. In consequence, it is difficult to deal with the original rural financial institutions in the area. In addition, with the emergence of the rural banks, rural mutual cooperatives, and new loan companies and the participation of other financial institutions and foreign banks, regulatory resources is difficult to be guaranteed."

Forced supervision means and ignorance of the endogenous cultivation of rural finance. The defect of the rural financial regulation system in China can be fully revealed in the development track of China Cooperation Fund in 1980s. As the quasi formal financial institutions mainly dependent on farmers' inject funds, rural cooperative fund business activities are charged by the Ministry of Agriculture rather than Chinese People's Bank, whose purpose is to establish connection between the national agricultural policy and rural financial strength, and achieved some positive results. However, due to the deviation from the original intention in the actual operation and the disobey of mutual purpose of the cooperation foundation, the administrative color is heavy and the intervention is serious, which causes a "run on a bank" storm and it is finally banned.

The reform process of rural credit cooperatives in China is obviously not fully drawing lessons from the agricultural foundation. Instead, it still adopted that the government puts forward the reform schemes from top to bottom, and then turn around and execute. The way neglects to foster rural financial market endogenous forces, which does not reserve necessary system space for farmers financial innovation and reform. In fact, the provincial and county union pattern deprived farmers' rights of the rural credit cooperatives as a shareholder, and insider control phenomenon has not changed [4]. What' s worse, some local governments peel off the non-performing assets and introduce central bank funding. In order to achieve the central bank bill, they take illegal dividend 
resort to deceit to attract farmers shares, which results in that the rural credit agency financial cooperation mechanism completely failed to reflect the farmers' willingness to participate in and failed to form a perfect corporate governance structure. As a result, the boundary between the supervision and management is fuzzy.

Incomplete restraint and guarantee mechanism. Supervision is the abbreviation of supervision and management. Supervision refers to the general care, supervision or examination; management refers to the decision, establishment or control. It is to adjust according to certain rules, method or model established, to guide according to rules or restrictions, and to be managed by management principles or laws. It is seen that, supervision and management is the set of a series of control measures." "An effective financial risk control system should consist of three systems: external bank, securities and insurance risk monitoring system under market constraints, internal control system of the supervised financial institutions, and social supervision system." The defect of rural financial supervision system in China lies in the lack of the industry self-regulation and internal governance as well as agricultural insurance, deposit insurance mechanism, and supervision guarantee system, failing to form a complete constraint and guarantee mechanism [5]. For instance, the rural credit cooperatives, because of the defects of property rights system and the corporate governance structure, the internal control mechanism cannot be effectively established. In addition, China Banking Association Working Committee is defined as the rural financial organization with self-discipline, which was founded in the end of 2005. The relationship between its specification objects, regulations, and legal relations is not clear. The organization is not extended to the rural grass-roots level, and the mechanism of self-discipline and self-management is still blank in China's rural financial market. China's agricultural insurance system and deposit insurance system were not established, lacking aid system and exit mechanism of rural financial institutions.

\section{Conception of perfecting rural financial supervision system in China}

China's rural finance has no specific performance of supervision system. The uniform of all the rural financial institutions into the current regulatory framework provides the convenience for the supervision of regulators. But this guide does not conform to the supervision requirements of the existing rural financial institutions which are corresponding to the particularity. And it will encourage the newly established financial institution management to develop towards commercial bank mode, making the service for rural areas and farmers become just a form. In view of this, this chapter, combining the characteristics of rural finance and the reality of our country, puts forward the following conception to perfect the rural financial supervision system in China.

Improve legislation and improve the legal system of rural financial supervision. Improve the basic legislation of rural finance and establish the overall framework and basic system of rural finance. The legal problems have a direct impact on China's financial ecological environment." The lack of laws regulation in the overall structure of the rural financial system fails to constitute the overall outline of the rural financial regulation. In Chinese agricultural basic law, only the "People's Republic of China Agricultural Law" has a provision for rural financial settings, and the provision stipulates the principles are extremely difficult to achieve the overall structure and the overall standard of rural financial market. Therefore, we should perfect the rural financial legislation at the level of the basic law. In the existing law in China, it is necessary to revise "People's Republic of China Agriculture Law", to set a special chapter on the overall framework and fundamental system of China's rural financial system, and to highlight the unique attributes and system needs of rural finance [6]. In addition, we should pay attention to the coordination of rural business finance, policy of rural finance and rural cooperative finance. According to the asymmetry of rural finance and commercial finance, we need to focus on the establishment of the rural financial market with cooperative finance and policy finance as the main body. At the same time, we are supposed to clarify the attitude towards the commercial finance business, guide the commercial finance to play a positive role in the rural financial market, and avoid capital back-flow, functional dislocation and so on phenomena. 
The informal rural financial organizations will be incorporated into the financial regulatory system to promote the formation of a diversified competition in the rural financial system. The informal rural finance "based on the relationship of rural social kinship and geopolitical relations, information superiority and transaction cost advantage has brought higher benefits to the circulation and operation of financial capital, which to a certain extent forms the pattern of competition with formal finance. The existence of competition must require legislation to create a fair environment for competition." Therefore, we should strengthen the legislation, and incorporate the informal rural finance into the financial regulatory system, and recognize the legal status in law. Through the relevant laws, regulations and supervision system, we should regulate the market access, business activities and related legal liability and market exit mechanism, and guide them to give full play to advantages in legal path.

Pay attention to the cultivation of rural financial endogenous forces. China's rural financial supervision gradually evolves from being concerned with the administrative management of institutions, business and market access and regulatory compliance to the prudential risk supervision as the center. It becomes more mature in the regulatory philosophy, standards and methods. Rural finance has its own characteristics and it is difficult to meet the current situation of rural financial needs, which decided that, in rural financial regulatory philosophy, it is different from the urban commercial finance.it requires that the setting of rural financial supervision system can, on the basis of risk prevention, promote the breeding and growth in rural finance with more tolerant institutional environment. In view of this, in the concept of rural financial supervision, we should focus on the cultivation of the endogenous forces of rural finance.

The essential purpose of financial supervision is to create favorable internal and external environment for the innovation and development of the financial industry, not to restrict the development of rural finance. To achieve the goal of cultivating a mature rural financial market and strengthening the guidance of rural financial institutions, service orientation and services in the field of the regulatory objectives, in the specific system, it is clearly reflected in the supervision setting of rural financial market access [7]. The construction of internal control mechanism of rural financial institutions is especially targeted for the reform of rural credit cooperatives in China. The supervision of rural cooperative finance should focus on supervision and improvement of corporate governance structure and internal control system." In the rural financial supervision, the corporate governance structure embodies as the formation, expression and realization of the voluntary members of the grass-roots cooperative financial organizations through a perfect governance structure. Since the grass-roots members are the bodies most closely related to the financial needs and understand the financing status, they can carry out the most direct, flexible and practical supervision and management of the issue of funds, the use of loans and the recovery of loans. For China's rural finance to meet the capital needs of rural areas and realize the function of supporting the rural economic and social development, it also needs to set up the reasonable and orderly corporate governance structure, form the effective internal control mechanism on this basis, and promote the growth and norms of rural financial endogenous forces.

Construct rural financial risk prevention system and market withdrawal mechanism. On the one hand, it is necessary to improve the social credit information system and establish a rural credit information sharing mechanism. As discussed earlier, the rural financial market information has a serious defect - asymmetry, and the defect not only constitutes the theoretical basis of Economics Regulation of rural financial market, but also results in non-performing assets, increase of transaction costs and financial risk. In the framework of the existing legal resources, we should speed up the development and introduction of "Regulations of People's Republic of China Credit Management, establish social credit system perfect, correct dishonest behavior in the rural financial market, and realize the sharing of credit information between the regulatory bodies [8]. On the other hand, we need to build a complete agricultural insurance system. The agricultural insurance systems in developed countries and financial countries all exist as an important part of the rural financial system. For high risk and low income rural finance, "Agricultural insurance legislation and development, as an induced institutional change, its legislation significance is far beyond the general commercial 
normative legal system". Therefore, besides the "People's Republic of China Insurance Law", we should make the special legislation, enact the "People's Republic of China Agricultural Insurance Law", and construct the agricultural insurance system in the path of legal norms, so as to provide perfect risk guarantee mechanism for rural financial development.

\section{Conclusion}

Based on the analysis and demonstration, we draw the following conclusions: first, we should realize that, although the unified supervision is a target for the development of the financial industry, at this stage, we should set up specialized for rural financial supervision system, and make settings and regulations in accordance with their own characteristics of rural finance in all aspects of the regulatory philosophy, regulatory objectives and the methods of supervision and so on. Specifically, in the regulatory philosophy, we should focus on the cultivation of rural financial endogenous forces, provide a tolerant system environment for the rural financial endogenous forces with guiding the rural financial services, service areas and improvement of the efficiency as the supervision objectives, and gradually overcome its weakness. Secondly, we should establish a standardized, unified, authoritative and orderly legal system for rural financial supervision, and draw up the basic law of rural finance, and make a special legislation on policy finance, cooperative finance and other important financial entities. Thirdly, in view of the disadvantages of excessive administrative interference and non agricultural tendency in the rural financial supervision, we should pay attention to the divestiture of the local government in the setting of the subject of rural financial supervision.

\section{References}

[1] Vittas, D., Queisser, M., Alier, M., James, E., Smalhout, J., Campanaro, A., ... \& Mokoli, M. (2016). Caprio, Gerard The dramatic events of the late 1990s brought the issue of financial sector policy in developing countries to the forefront. Much of the international community's policy focuses on financial sector reform including strengthening the prudential regulations and supervision of the financial system alon [...] 20 jul 2016, 16: 38: 14. Policy,16(24), 42.

[2] Zhou, J., Hao, Y., Jin, F., \& Zhou, J. (2017). Shanxi Merchants’ Multilevel Financial System in Ming and Qing Dynasties, China. Emerging Markets Finance and Trade, 53(2), 376-386.

[3] Wilson, J. P., \& Campbell, L. (2016). Financial functional analysis: a conceptual framework for understanding the changing financial system.Journal of Economic Methodology, 23(4), 413-431.

[4] Cheng, H. (2016). The Financial System in China: Financial Sectors, State Influences, and Opportunities for Crime. In Financial Crime in China (pp. 1-19). Palgrave Macmillan US.

[5] Lu, Y. H. (2016). Driving force or obstruction? The impacts of financial supervision and structural changes on the productivity of the Credit Departments of Farmers' Associations. China Agricultural Economic Review,8(2), 314-334.

[6] Castellanos, S. G., Del Ángel, G. A., \& Garza-García, J. G. (2016). Competition Policy in the Mexican Financial System. In Competition and Efficiency in the Mexican Banking Industry (pp. 125-158). Palgrave Macmillan US.

[7] Sun, F. J. (2016). A Game Analysis of Quality Supervision Over Rural Development Projects. In Proceedings of the 22nd International Conference on Industrial Engineering and Engineering Management 2015 (pp. 185-192). Atlantis Press.

[8] Pant, P. R., Ellis, M., Deave, T., \& Mytton, J. (2016). 699 Community mobilisation to establish a community creche to increase child supervision in rural nepal. Injury Prevention, 22(Suppl 2), A251-A251. 